\title{
Optimal Path Solution Using Dijkstra's Algorithm for Practical 21 bus system
}

\author{
K.Venkat Rao ${ }^{1}$ | Dr.K.RamaSudha ${ }^{1}$ \\ Dept of EE, AUCE, Andhra University
}

\section{To Cite this Article}

K.Venkat Rao and Dr.K.RamaSudha, "Optimal Path Solution Using Dijkstra's Algorithm for Practical 21 bus system", International Journal for Modern Trends in Science and Technology, 6(12): 502-509, 2020.

Article Info

Received on 16-November-2020, Revised on 09-December-2020, Accepted on 12-December-2020, Published on 21-December-2020.

\section{ABSTRACT}

This paper presents the Shortest Path Finding algorithm to identify the optimal path for a distribution system during restoration using Dijkstra's method. The objective is to reduce the power losses and obtain an efficient restoration plan after an extensive outage of the system. The power losses of the distribution system are calculated using Forward-Backward sweep load flow method. The proposed method has been implemented for a practical 21 bus distribution system using MATLAB programming .

KEYWORDS-Shortest Path Finding; Dijkstra's method; Forward-Backward Sweep load flow method

\section{INTRODUCTION}

The Load flow analysis is a best as well as an elementary tool to study the power system engineering. Today we have lots of methods to study the load flow analysis like Newton Raphson Method, Gauss-siedel Method, Fast decoupled method, but those methods are great match for Transmission system. But unlike transmission system, distribution system has well-known different characteristics; some of them are as shown below:-

- Radial or weakly meshed structure;

- High R/X ratios of the feeders;

- Multi-phase and unbalanced operation;

- Unbalanced distributed load;

- $\quad$ Exceedingly large number of branches and nodes;

- Comprehensive resistance and reactance values.
Hence there is a requirement of an efficient and robust technique to handle the deal. the traditional load flow methods used in transmission systems; fail to meet the requirements in both performance and robustness aspects in the distribution system applications because of above mentioned features. Precisely, the assumptions necessary for the simplifications used in the standard fast-decoupled Newton method [1] often losses it's validity in distribution systems. Thus, a novel load flow algorithm for distribution systems is desired. All of the characteristics mentioned before must be considered, to qualify for a good distribution load flow algorithm.

There are lots of algorithms specifically designed for distribution systems have been suggested in the literature [2]. Most of these methods are derived from transmission networks and based on general meshed topology. Among those methods; Gauss implicit Z-matrix method is highly fashionable but when it comes to the 
distribution network, this method does not clearly exploit the radial and weakly meshed network structure of distribution systems and, therefore, a solution of a set of equations whose size is proportional to the number of buses is required. Several other techniques, such as the $3-\varnothing$ fast decoupled power flow algorithm [3], the Newton-Raphson method and phase decoupled method [4] etc., have also been anticipated. Another direct approach, which utilizes two matrices developed from the topological characteristics of the distribution system, is proposed in this paper work.

But, the dominance of the backward and forward sweep method(BFSM); over other solution techniques as it is fast for solving the load flow of radial distribution systems and effective; makes it more valuable. The ill-conditioned nature arising due to high $\mathrm{R} / \mathrm{X}$ ratios of the feeders are taken care of by The "BFSM", which eradicate the need of Fast decoupled Newton Method and Gauss Method. This techniques model the distribution network as a tree with the slack bus as the root. The backward sweep predominantly sums bus current to finally evaluate the branch current. And the forward sweep is used to calculate voltage drop, which provide updates to the voltage profile constructed from the current estimation of the flows.

Power system restoration following a partial or total blackout is one of the most important tasks for power system operators. It is a complex process that restores the system back to normal after an extensive outage of the system. Due to a combination of unforeseen circumstances, there is a remote possibility of a system -wide outage and it is very important not only to minimize power failure, but also restore the power system network quickly and safely.

To find the shortest path in the weighted network, the following SPF algorithms are used.

- Dijkstra's algorithm solves the single-pair, single-source, and single-destination shortest path problems.

- Bellman Ford algorithm solves the single source problem if edge weights may be negative.

- Floyd Warshall algorithm solves all pairs shortest paths.

\section{OVERVIEW OF FORWARD-BACKWARD SWEEP LOAD FLOW METHOD}

\section{A.Formulation of The Problem}

The Power flows in a distribution system are computed by the following set of simplified recursive equations. The power flow analysis can be used to obtain the voltage magnitude, power losses of the 33 bus system. The objective function is to find the power flow.

$$
\begin{aligned}
& P_{k+1}=P_{k}-P_{\text {loss }, k^{-}} P_{L k+1} \\
& Q_{k+1}=Q_{k}-Q_{\text {loss }, k^{-}} Q_{L k+1}
\end{aligned}
$$

where $P_{k}$ - Real power flowing out of bus; $Q_{k}$ Reactive power flowing out of bus; $\mathrm{P}_{\mathrm{Lk}+1^{-}}$Real load power at bus k+1; $\mathrm{Q}_{\mathrm{Lk}+1}-$ Reactive load power at bus $\mathrm{k}+1$

The power loss in the line section connecting buses $\mathrm{k}$ and $\mathrm{k}+1$ may be computed as

$$
\begin{aligned}
& P_{\text {loss }}(k, k+1)=R_{k} \frac{P_{k}{ }^{2}+Q_{k}{ }^{2}}{V_{k}{ }^{2}} \\
& Q_{\text {loss }}(k, k+1)=X_{k} P_{k}{ }^{2+} Q_{k}{ }^{2}
\end{aligned}
$$

Where, $\mathrm{P}_{\text {loss }}(\mathrm{k}, \mathrm{k}+1)$ - Real power Loss in the line section connecting buses $\mathrm{k}$ and $\mathrm{k}+1$;

$\mathrm{Q}_{\text {loss }}(\mathrm{k}, \mathrm{k}+1)$ - Reactive power Loss in the line section connecting buses $\mathrm{k}$ and $\mathrm{k}+1$.

The total power loss of the feeder, $\mathrm{P}_{\mathrm{T}, \text { loss }}$ may then be determined by summing up the losses of all line sections of the feeder, which is given as

$$
\begin{aligned}
\mathrm{P}_{\mathrm{T}, \text { loss }}(\mathrm{k}, \mathrm{k}+1) & =\sum_{k=1}^{n} \operatorname{Ploss}(\mathrm{k}, \mathrm{k}+1) \\
\mathrm{Q}_{\mathrm{T}, \text { loss }}(\mathrm{k}, \mathrm{k}+1) & =\sum_{k=1}^{n} \operatorname{Qloss}(\mathrm{k}, \mathrm{k}+1)
\end{aligned}
$$

where $\mathrm{P}_{\mathrm{T}, \text { loss }}(\mathrm{k}, \mathrm{k}+1)$ - Total Real Power Loss in the line section; $\mathrm{Q}_{\mathrm{T}, \text { loss }}$ - Total Reactive Power Loss in the line section

\section{B. Forward-Backward Sweep Method}

Let us consider a radial network, the backward/forward sweep method for the load-flow computation is an iterative method in which, at each iteration two computational stages are performed: The load flow of a single source network can be solved iteratively from two sets of recursive equations. The first set of equations for calculation of the power flow through the branches starting from the last branch and proceeding in the backward direction towards the root node. The other set of equations are for calculating the voltage magnitude and angle of each node starting from the root node and proceeding in the forward direction towards the last node.

\section{i. Forward Sweep}

The forward sweep is basically a voltage drop calculation with possible cur-rent or power flow updates. Nodal voltages are updated in a forward sweep starting from branches in the first layer toward those in the last. The purpose of the forward propagation is to calculate the voltages at each node starting from the feeder source node. The feeder substation voltage is set at its actual 
value. During the forward propagation the effective power in each branch is held constant to the value obtained in backward walk.

\section{ii. Backward Sweep}

The backward sweep is basically a current or power flow solution with possible voltage updates. It starting from the branches in the last layer and moving towards the branches connected to the root node. The updated effective power flows in each branch are obtained in the backward propagation computation by considering the node voltages of previous iteration. It means the voltage values obtained in the forward path are held constant during the backward propagation and updated power flows in each branch are transmitted backward along the feeder using backward path. This indicates that the backward propagation starts at the extreme end node and proceeds towards source node.

It is well known that there exist three main variants of the forward/backward sweep method that differ from each other based on the type of electric quantities that at each iteration, starting from the terminal nodes and going up to the source node (backward sweep), are calculated.

1. The current summation method, in which the branchcurrents are evaluated;

2. The power summation method, in which the power flows

in the branches are evaluated;

3. The admittance summation method, in which, node by

node, the driving point admittances are evaluated. In other terms, the three variants of the $\mathrm{B} / \mathrm{F}$ method simulate the loads within each iteration, with a constant current, a constant power and a constant admittance model. In the forward phase, the three variants are identical since, based on quantities calculated in the backward phase, the bus voltages are calculated starting from the source node and going towards the ending nodes. Voltages are then used to update, based on the dependency of loads on the voltage, the quantities used in the backward sweep in order to proceed to iteration. The process stops when a convergence criterion is verified.

By comparing the calculated voltages in previous and

present iterations, the successive iteration is obtained. The convergence can be achieved if the voltage mismatch is less than the specified tolerance i.e., 0.0001. Otherwise new effective power flows in each branch are calculated through backward walk with the present computed voltages and then the procedure is repeated until the solution is converged.

The backward/forward sweep method is now reformulated in a way suitable for the analysis of the convergence of the iterative process. A branch is connected between the nodes ' $\mathrm{k}$ ' and ' $\mathrm{k}+1$ '. The effective active $\left(P_{k}\right)$ and reactive $\left(Q_{k}\right)$ powers that of flowing through branch from node ' $\mathrm{k}$ ' to node ' $\mathrm{k}+1$ ' can be calculated backwards from the last node and is given as,

$$
\begin{aligned}
& P_{k}=P^{\prime}{ }_{k+1}+r_{k} \frac{\left(P^{2}{ }_{k+1}+Q^{2}{ }_{k+1}\right)}{V^{2}{ }_{k+1}} \\
& Q_{k}=Q{ }_{k+1}+x_{k} \frac{\left(P^{2}{ }_{k+1}+Q^{2}{ }_{k+1}\right)}{V^{2}{ }_{k+1}}
\end{aligned}
$$

where

$$
\begin{aligned}
P^{\prime}{ }_{k+1} & =P_{k+1}+P_{L k+1} \\
Q^{\prime}{ }_{k+1} & =Q_{k+1}+Q_{L k+1}
\end{aligned}
$$

$\mathrm{P}_{\mathrm{Lk}+1}$ and $\mathrm{Q}_{\mathrm{Lk}+1}$ are loads that are connected at node ' $\mathrm{k}+1$ ', $\mathrm{P}_{\mathrm{k}+1}$ and $\mathrm{Q}_{\mathrm{k}+1}$ are the effective real and reactive power flows from node ' $\mathrm{k}+1$ '.

The voltage magnitude and angle at each node are calculated in forward direction. Consider a voltage $\mathrm{V}_{\mathrm{k}}<\delta_{\mathrm{k}}$ at node ' $\mathrm{k}$ ' and $\mathrm{V}_{\mathrm{k}+1}<\delta_{\mathrm{k}+1}$ at node ' $\mathrm{k}+1$ ', then the current flowing through the branch having an impedance, $z_{k}=r_{k}+x_{k}$ connected between ' $\mathrm{k}$ ' and ' $\mathrm{k}+1$ 'is given as,

$$
\mathrm{I}_{\mathrm{k}}=\frac{\mathrm{V}_{\mathrm{k}}<\delta_{\mathrm{k}}-\mathrm{V}_{\mathrm{k}+1}<\delta_{\mathrm{k}+1}}{\mathrm{r}_{\mathrm{k}}+\mathrm{j} \mathrm{x}_{\mathrm{k}}}
$$

The magnitude and the phase angle equations can be used recursively in a forward direction to find the voltage and angle respectively of all nodes of radial distribution system.

Initially, a flat voltage profile is assumed at all nodes i.e., $1.0 \mathrm{pu}$. The branch powers are computed iteratively with the updated voltages at each node. In the proposed load flow method, power summation is done in the backward walk and voltages are calculated in the forward walk.

\section{OVERVIEW OF DIJKSTRA'S ALGORITHM}

\section{A. Description}

Dijkstra's algorithm, formulated by the Edsger Dijkstra in 1959, is a graph search algorithm that obtains solution in the single pair, single source and single destination shortest path problem. This algorithm obtains the solution if the path has non negative weight. For a given source vertex (node) in the graph, the algorithm finds the path with the lowest cost between that vertex and every other vertex. For example, if the vertices of the graph represent cities and the edge path cost represent the driving distances between pairs of cities connected by a direct road, Dijkstra's algorithm is used to find the shortest route between one city 
and all the other cities. As a result, the optimal path for the transmission of power in the electrical network is obtained by the extended Dijkstra's algorithm.

B. PseudoCode

void

Dijkstra(Table T)

\{

Vertex v, w;

for ( ; ;

$\mathrm{v}=$ smallest unknown distance vertex;

if $(\mathrm{v}==$ Not a Vertex $)$

break;

$\mathrm{T}[\mathrm{v}]$. known $=$ True;

for each $\mathrm{w}$ adjacent to $\mathrm{v}$

if (! T[w].known)

if(T[v].dist + Cvw $<\mathrm{T}[\mathrm{w}] \cdot$ dist $)$

$\left\{l^{*}\right.$ update $\mathrm{w} * /$

Decrease ( $\mathrm{T}[\mathrm{w}]$.dist to $\mathrm{T}[\mathrm{v}]$.dist $+\mathrm{Cvw}$ ); $\mathrm{T}[\mathrm{w}] \cdot \mathrm{path}=\mathrm{v}$;

\}

\section{Algorithmic Steps}

The following procedure is to be executed to find the shortest path in the network.

1. Let the starting node be called an initial node. Dijkstra's algorithm will assign some initial distance value to the edges and it will try to improve them step-by-step.

2 . Set the distance value to zero for the initial node and to infinity for all the other nodes.

3. Mark all nodes as unvisited. Set the initial node as current node.

4. For a current node, consider all its unvisited nodes and

calculate their distance using Equation 10. (from the initial node).

$$
\mathrm{d} \mathrm{w}=\mathrm{d} \mathrm{v}+\mathrm{d} \mathrm{v}, \mathrm{w}
$$

where $d w$ be the distance of the vertex $w, d v$ be the distance of the vertex $\mathrm{v}$ and $\mathrm{dv}$, $\mathrm{w}$ be the distance between the vertex $\mathbf{v}$ and $\mathbf{w}$. For example, if the current node (A) has a distance of 6 , and an edge connecting it with another node $(B)$ is 2 , the distance to $B$ through $A$ will be $6+2=8$. If this distance is less than the previously recorded distance, replace it with the new calculated value. 5. The distance between the current node and all its neighbours is calculated using the Equation 10. Then, the corresponding nodes are marked as visited. A visited node will not be checked ever again; its distance recorded now is final and minimal.
6. Set the unvisited node which is having the smallest distance (from the initial node) as the next "current node" and continue from step 3.

\section{APPLICATION OF DIJKSTRA'S ALGORITHM TO LOAD FLOW}

\section{A. Flow Chart}

The proposed method is shown in detail using the below flow chart as follows.

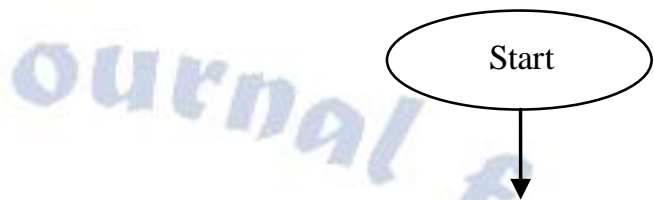

Read line data, load data \& length data

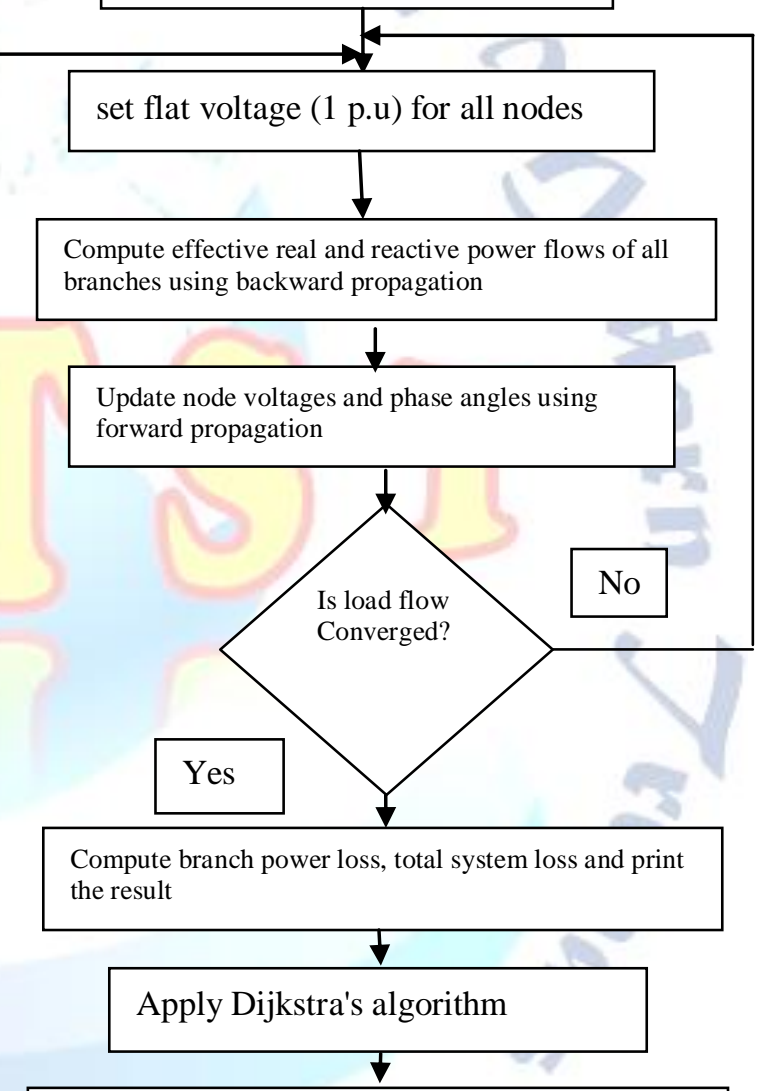

Enter the source and destination nodes between which the path has to be determined

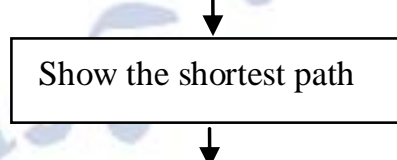

enter no. of faulted lines (n)

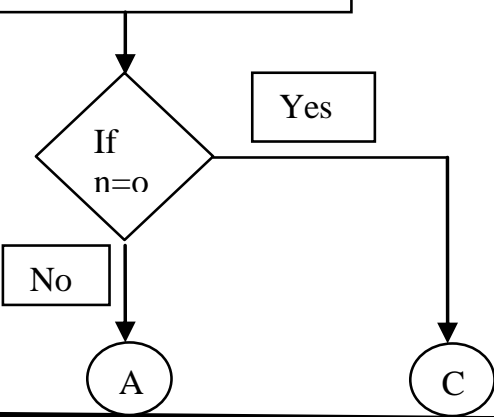




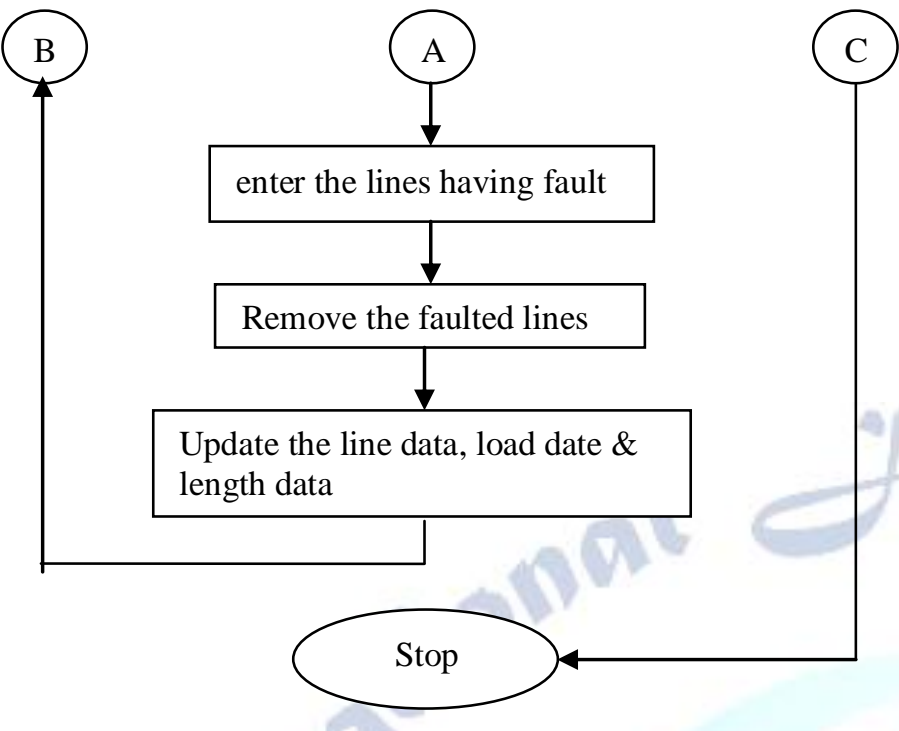

\section{V. . SIMULATION RESULTS}

The suitability of the proposed method has been tested for a practical distribution system having 21 bus shown in Fig. 1. The practical 21 bus system has 37 lines connecting different places in a particular city which are represented by bus numbers. The values of resistance, reactance, real power, reactive power at each bus is shown in the Table 1 . The length of the line between different source and destination buses are shown in the Table 2.

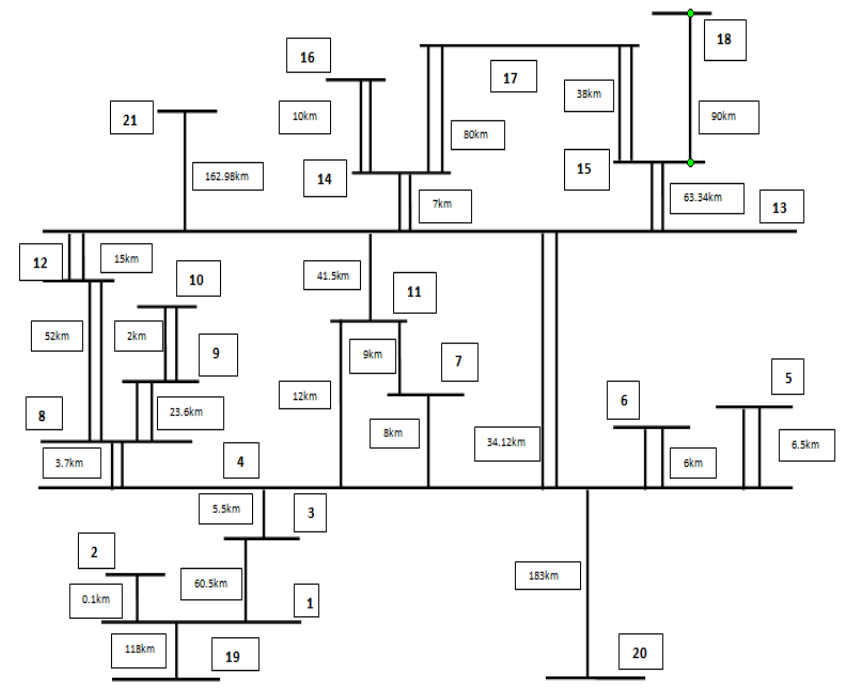

Fig 1. Practical 21bus system

TABLE 1 : SYSTEM LINE DATA

\begin{tabular}{|c|c|c|c|c|c|c|}
\hline $\begin{array}{c}\text { Line } \\
\text { Number }\end{array}$ & $\begin{array}{c}\text { From } \\
\text { bus }\end{array}$ & $\begin{array}{c}\text { To } \\
\text { bus }\end{array}$ & $\begin{array}{c}\text { Resistance } \\
\text { (ohms) }\end{array}$ & $\begin{array}{c}\text { Reactance } \\
\text { (ohms) }\end{array}$ & $\begin{array}{c}\mathbf{P} \\
\text { (Mw) }\end{array}$ & $\begin{array}{c}\mathbf{Q} \\
\text { (MVar) }\end{array}$ \\
\hline 1 & 2 & 1 & 0.003 & 0.015 & 101 & 8.10 \\
\hline 2 & 1 & 19 & 3.54 & 17.7 & 131 & 1.71 \\
\hline 3 & 1 & 3 & 1.815 & 9.075 & -11.4 & 8.91 \\
\hline 4 & 3 & 4 & 0.165 & 0.825 & 115 & 10 \\
\hline 5 & 4 & 20 & 5.49 & 27.45 & 85 & 10 \\
\hline 6 & 4 & 8 & 0.111 & 0.555 & 110 & 0 \\
\hline 7 & 4 & 8 & 0.111 & 0.555 & 110 & 0 \\
\hline
\end{tabular}

\begin{tabular}{|c|c|c|c|c|c|c|}
\hline 8 & 4 & 11 & 0.36 & 1.8 & 120 & 0 \\
\hline 9 & 4 & 7 & 0.24 & 1.2 & 80 & 0 \\
\hline 10 & 4 & 13 & 1.0236 & 5.118 & 85 & 6 \\
\hline 11 & 4 & 13 & 1.0236 & 5.118 & 85 & 6 \\
\hline 12 & 4 & 6 & 0.18 & 0.9 & 20 & 0 \\
\hline 13 & 4 & 6 & 0.18 & 0.9 & 20 & 0 \\
\hline 14 & 4 & 5 & 0.015 & 0.075 & 200 & 0 \\
\hline 15 & 4 & 5 & 0.015 & 0.075 & 180 & 0 \\
\hline 16 & 7 & 11 & 0.27 & 1.35 & 84 & -3 \\
\hline 17 & 8 & 12 & 1.56 & 7.8 & 52 & -8 \\
\hline 18 & 8 & 12 & 1.56 & 7.8 & 52 & -7 \\
\hline 19 & 8 & 9 & 0.708 & 3.54 & 61 & 13.3 \\
\hline 20 & 8 & 9 & 0.708 & 3.54 & 0 & 11.47 \\
\hline 21 & 9 & 10 & 0.06 & 0.3 & 4.03 & 0.14 \\
\hline 22 & 9 & 10 & 0.06 & 0.3 & 4.03 & 0.14 \\
\hline 23 & 11 & 13 & 1.245 & 6.225 & 32 & 13 \\
\hline 24 & 12 & 13 & 0.45 & 2.25 & 32 & -2.4 \\
\hline 25 & 12 & 13 & 0.45 & 2.25 & 33 & -1 \\
\hline 26 & 13 & 14 & 0.21 & 1.05 & 30 & -2 \\
\hline 27 & 13 & 14 & 0.21 & 1.05 & 30 & -2 \\
\hline 28 & 13 & 21 & 4.8894 & 24.447 & 21 & 9 \\
\hline 29 & 13 & 15 & 1.9002 & 9.501 & 115 & 24 \\
\hline 30 & 13 & 15 & 1.9002 & 9.501 & 115 & 24 \\
\hline 31 & 14 & 16 & 0.3 & 1.5 & 27.2 & 223 \\
\hline 32 & 14 & 16 & 0.3 & 1.5 & 27.2 & 223 \\
\hline 33 & 14 & 17 & 2.4 & 12 & 0 & 0 \\
\hline 34 & 14 & 17 & 2.4 & 12 & 0 & 0 \\
\hline 35 & 15 & 17 & 1.14 & 5.7 & 0 & 0 \\
\hline 36 & 15 & 17 & 1.14 & 5.7 & 0 & 0 \\
\hline 37 & 15 & 18 & 2.7 & 13.5 & 62 & 10 \\
\hline
\end{tabular}

TABLE 2 : SYSTEMS LENGTH DATA

\begin{tabular}{|c|c|c|c|}
\hline Line Number & From bus & To bus & Length (km) \\
\hline 1 & 2 & 1 & 0.1 \\
\hline 2 & 1 & 19 & 118 \\
\hline 3 & 1 & 3 & 60.5 \\
\hline 4 & 3 & 4 & 5.5 \\
\hline 5 & 4 & 20 & 183 \\
\hline 6 & 4 & 8 & 3.7 \\
\hline 7 & 4 & 8 & 3.7 \\
\hline 8 & 4 & 11 & 12 \\
\hline 9 & 4 & 7 & 8 \\
\hline 10 & 4 & 13 & 34.12 \\
\hline 11 & 4 & 13 & 34.12 \\
\hline 12 & 4 & 6 & 6 \\
\hline 13 & 4 & 6 & 6 \\
\hline 14 & 4 & 5 & 0.5 \\
\hline 15 & 4 & 5 & 0.5 \\
\hline 16 & 7 & 11 & 9 \\
\hline 17 & 8 & 12 & 52 \\
\hline 18 & 8 & 12 & 52 \\
\hline 19 & 8 & 9 & 23.6 \\
\hline 20 & 8 & 9 & 23.6 \\
\hline 21 & 9 & 10 & 2 \\
\hline 22 & 9 & 10 & 2 \\
\hline 23 & 11 & 13 & 41.5 \\
\hline 24 & 12 & 13 & 15 \\
\hline 25 & 12 & 13 & 15 \\
\hline 26 & 13 & 14 & 7 \\
\hline 27 & 13 & 14 & 7 \\
\hline 28 & 13 & 21 & 162.98 \\
\hline 29 & 13 & 15 & 63.34 \\
\hline 30 & 13 & 15 & 63.34 \\
\hline 31 & 14 & 16 & 10 \\
\hline 32 & 14 & 16 & 10 \\
\hline 33 & 14 & 17 & 80 \\
\hline 34 & 14 & 17 & 80 \\
\hline 35 & 15 & 17 & 38 \\
\hline 36 & 15 & 17 & 3 \\
\hline 37 & 15 & 18 & 90 \\
\hline
\end{tabular}


The current, voltage and power losses of each lines and buses before and after removing the faulted lines 5 and 6 are shown in the tables 3 and 4. The paths for applying the Dijkstra's algorithm is obtained as shown in table 5 .

The shortest path obtained between the buses 2 and 9 before and after removal of faulted lines is shown in figure 2 and 3 respectively.

TABLE 3 : OUTPUTS OBTAINED BEFORE AND AFTER REMOVING THE FAULTED LINES

\begin{tabular}{|c|c|c|c|c|c|}
\hline $\begin{array}{c}\text { Curren } \\
\text { t before } \\
\text { removi } \\
\text { ng } \\
\text { faulted } \\
\text { lines }\end{array}$ & $\begin{array}{l}\text { Curren } \\
\text { t after } \\
\text { removi } \\
\text { ng } \\
\text { faulted } \\
\text { lines }\end{array}$ & $\begin{array}{l}\text { Voltage } \\
\text { before } \\
\text { removi } \\
\text { ng } \\
\text { faulted } \\
\text { lines }\end{array}$ & $\begin{array}{l}\text { Voltage } \\
\text { after } \\
\text { removi } \\
\text { ng } \\
\text { faulted } \\
\text { lines }\end{array}$ & $\begin{array}{c}\text { Power } \\
\text { loss } \\
\text { before } \\
\text { removi } \\
\text { ng } \\
\text { faulted } \\
\text { lines }\end{array}$ & $\begin{array}{l}\text { Power } \\
\text { loss } \\
\text { after } \\
\text { removi } \\
\text { ng } \\
\text { faulted } \\
\text { lines }\end{array}$ \\
\hline 8.4210 & 5.4227 & 0.9992 & 1.0004 & 0.0013 & 0.0006 \\
\hline 0.1313 & 0.1319 & 1.0000 & 1.0000 & 0.0004 & 0.0004 \\
\hline 8.3247 & 5.6141 & 0.5311 & 1.2616 & 0.7848 & 0.3569 \\
\hline 8.3241 & 5.6132 & 0.4898 & 1.2867 & 0.0713 & 0.0324 \\
\hline 0.0521 & 2.6565 & 0.4898 & 1.2867 & 0.0001 & 0.0049 \\
\hline 2.6855 & 0.6904 & 0.4898 & 1.2867 & 0.0050 & 0.0011 \\
\hline 2.6855 & 0.7093 & 0.4848 & 1.2913 & 0.0050 & 0.0008 \\
\hline 0.6927 & 0.6549 & 0.4808 & 1.2951 & 0.0011 & 0.0027 \\
\hline 0.7068 & 0.6549 & 0.4806 & 1.2953 & 0.0007 & 0.0027 \\
\hline 0.6669 & 0.0165 & 0.4806 & 1.2953 & 0.0028 & 0.0000 \\
\hline 0.6669 & 0.0165 & 0.4792 & 1.2965 & 0.0028 & 0.0000 \\
\hline 0.0123 & 0.1648 & 0.4187 & 1.3535 & 0.0000 & 0.0000 \\
\hline 0.0123 & 0.1484 & 0.4099 & 1.3620 & 0.0000 & 0.0000 \\
\hline 0.1228 & 0.6730 & 0.4081 & 1.3637 & 0.0000 & 0.0008 \\
\hline 0.1105 & 1.2822 & 0.4073 & 1.3640 & 0.0000 & 0.0160 \\
\hline 0.6791 & 1.2828 & 0.4069 & 1.3649 & 0.0008 & 0.0160 \\
\hline 1.3060 & 0.0553 & 0.4073 & 1.3640 & 0.0166 & 0.0000 \\
\hline 1.3065 & 0.0112 & 0.4062 & 1.3649 & 0.0166 & 0.0000 \\
\hline 0.0429 & 0.0032 & 0.9960 & 0.9972 & 0.0000 & 0.0000 \\
\hline 0.0087 & 0.0032 & 0.4865 & 1.0000 & 0.0000 & 0.0000 \\
\hline 0.0025 & 0.6423 & 0.4086 & 1.3631 & 0.0000 & 0.0032 \\
\hline 0.0025 & 0.6347 & & & 0.0000 & 0.0011 \\
\hline 0.6543 & 0.6357 & & & 0.0033 & 0.0011 \\
\hline 0.6466 & 0.2577 & & & 0.0012 & 0.0001 \\
\hline 0.6476 & 0.2577 & & & 0.0012 & 0.0001 \\
\hline 0.2610 & 0.0131 & & & 0.0001 & 0.0000 \\
\hline 0.2610 & 0.1016 & & & 0.0001 & 0.0001 \\
\hline 0.0132 & 0.1016 & & & 0.0000 & 0.0001 \\
\hline 0.1037 & 0.1281 & & & 0.0001 & 0.0000 \\
\hline 0.1037 & 0.1281 & & & 0.0001 & 0.0000 \\
\hline 0.1297 & 0 & & & 0.0000 & 0 \\
\hline 0.1297 & 0 & & & 0.0000 & 0 \\
\hline 0 & 0 & & & 0 & 0 \\
\hline 0 & 0 & & & 0 & 0 \\
\hline 0 & 0.0352 & & & 0 & 0.0000 \\
\hline $\begin{array}{c}0 \\
0.0361\end{array}$ & & & & $\begin{array}{c}0 \\
0.0000\end{array}$ & \\
\hline
\end{tabular}

TABLE 4: TOTAL POWER LOSSES

\begin{tabular}{|c|c|}
\hline $\begin{array}{c}\text { Total Power } \\
\text { loss before } \\
\text { removing } \\
\text { faulted } \\
\text { lines }\end{array}$ & $\begin{array}{c}\text { Total Power } \\
\text { loss after } \\
\text { removing } \\
\text { faulted lines }\end{array}$ \\
\hline 0.9156 & 0.4413 \\
\hline
\end{tabular}

TABLE 5 :NODES WHICH ARE CONNECTED FOR OBTAINING SHORTEST PATH

\begin{tabular}{|c|c|c|c|}
\hline \multicolumn{2}{|c|}{$\begin{array}{l}\text { Path formed and thier } \\
\text { respective distances } \\
\text { before faulted lines } \\
\text { removal }\end{array}$} & \multicolumn{2}{|c|}{$\begin{array}{l}\text { Path formed and } \\
\text { thier respective } \\
\text { distances after } \\
\text { faulted lines } \\
\text { removal }\end{array}$} \\
\hline$(2,1)$ & 0.1000 & $(2,1)$ & 0.1000 \\
\hline$(1,3)$ & 60.5000 & $(1,3)$ & 60.5000 \\
\hline$(3,4)$ & 5.5000 & $(3,4)$ & 5.5000 \\
\hline$(5,4)$ & 0.5000 & $(5,4)$ & 0.5000 \\
\hline$(6,4)$ & 6.0000 & $(6,4)$ & 6.0000 \\
\hline$(8,4)$ & 3.7000 & $(8,4)$ & 3.7000 \\
\hline$(13,4)$ & 34.1200 & $(13,4)$ & 34.1200 \\
\hline$(4,5)$ & 0.5000 & $(4,5)$ & 0.5000 \\
\hline$(4,6)$ & 6.0000 & $(4,6)$ & 6.0000 \\
\hline$(5,7)$ & 8.0000 & $(5,7)$ & 8.0000 \\
\hline$(4,8)$ & 3.7000 & $(9,8)$ & 23.6000 \\
\hline$(9,8)$ & 23.6000 & $(12,8)$ & 52.0000 \\
\hline$(12,8)$ & 52.0000 & $(8,9)$ & 23.6000 \\
\hline$(8,9)$ & 23.6000 & $(10,9)$ & 2.0000 \\
\hline$(10,9)$ & 2.0000 & $(9,10)$ & 2.0000 \\
\hline$(9,10)$ & 2.0000 & $(5,11)$ & 12.0000 \\
\hline$(5,11)$ & 12.0000 & $(7,11)$ & 9.0000 \\
\hline$(7,11)$ & 9.0000 & $(8,12)$ & 52.0000 \\
\hline$(8,12)$ & 52.0000 & $(13,12)$ & 15.0000 \\
\hline$(13,12)$ & 15.0000 & $(5,13)$ & 34.1200 \\
\hline$(5,13)$ & 34.1200 & $(11,13)$ & 41.5000 \\
\hline$(11,13)$ & 41.5000 & $(12,13)$ & 15.0000 \\
\hline$(12,13)$ & 15.0000 & $(14,13)$ & 7.0000 \\
\hline$(14,13)$ & 7.0000 & $(15,13)$ & 63.3400 \\
\hline$(15,13)$ & 63.3400 & $(13,14)$ & 7.0000 \\
\hline$(13,14)$ & 7.0000 & $(16,14)$ & 10.0000 \\
\hline$(16,14)$ & 10.0000 & $(17,14)$ & 80.0000 \\
\hline$(17,14)$ & 80.0000 & $(13,15)$ & 63.3400 \\
\hline$(13,15)$ & 63.3400 & $(17,15)$ & 38.0000 \\
\hline$(17,15)$ & 38.0000 & $(14,16)$ & 10.0000 \\
\hline$(14,16)$ & 10.0000 & $(14,17)$ & 80.0000 \\
\hline$(14,17)$ & 80.0000 & $(15,17)$ & 38.0000 \\
\hline$(15,17)$ & 38.0000 & $(15,18)$ & 90.0000 \\
\hline$(15,18)$ & 90.0000 & $(1,19)$ & 118.0000 \\
\hline$(1,19)$ & 118.0000 & $(13,21)$ & 162.9800 \\
\hline$(4,20)$ & 183.0000 & & \\
\hline$(13,21)$ & 162.9800 & & \\
\hline 21 nodes & ind 37 edges & $21 \mathrm{noc}$ & $\begin{array}{l}\text { es and } 35 \\
\text { dges }\end{array}$ \\
\hline
\end{tabular}

Here, the outputs obtained after removal of 2 faulted lines is shown. Whereas, the program can be tested for finding shortest path after removal of any number of

faults. Any other method for shortest path calculation can also be used for further studies Figure 2: Shortest path between buses 2 and 9 before removing faulted lines 


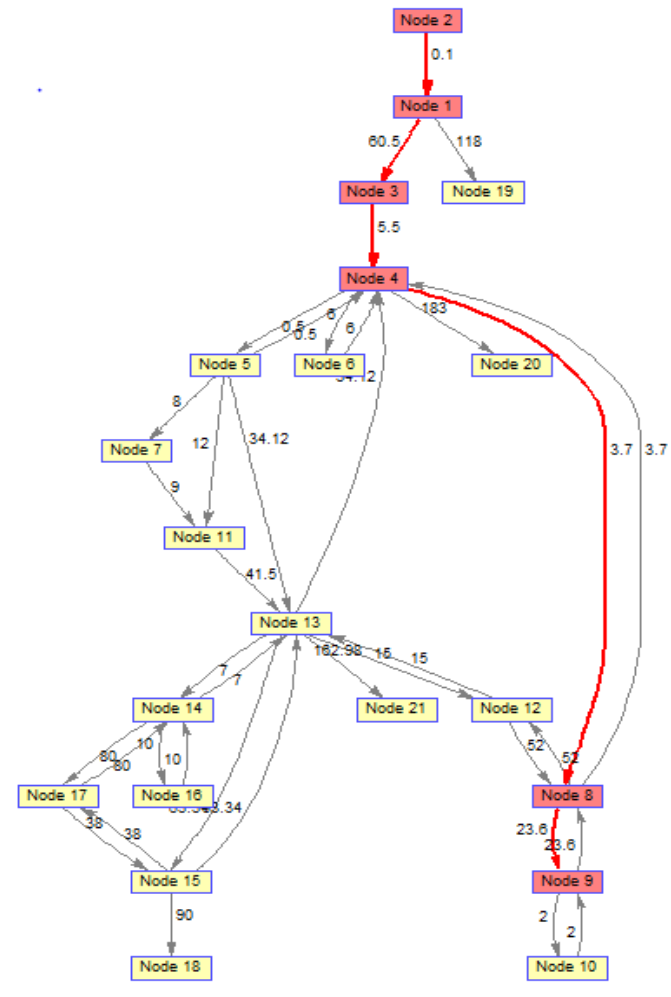

Figure 3: Shortest path between buses 2 and 9 after removing faulted lines

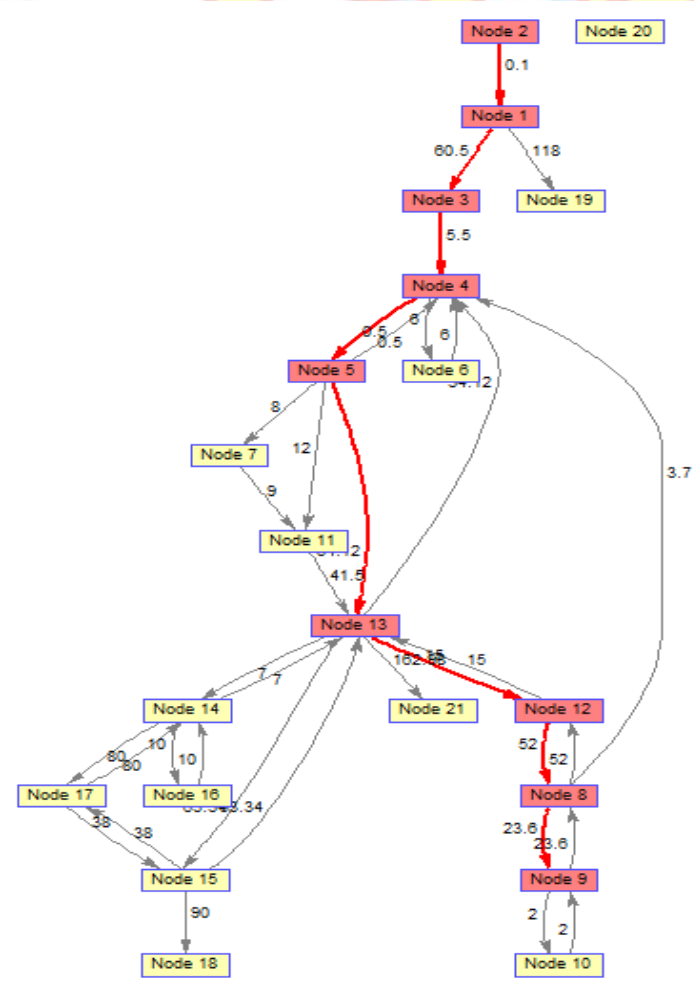

REFERENCES

[1] K. A. Birt, J. J. Graffy, J. D. McDonald, and A. H. El-Abiad, "Three phase load flow program," IEEE Trans. Power Apparat. Syst., vol. PAS-95, pp. 59-65, Jan. /Feb. 1976
[2] T.-H. Chen, M.-S.Chen, K.-J. Hwang, P. Kotas, and E. A. Chebli, "Distribution system power flow analysis-A rigid approach," IEEE Trans. Power Delivery, vol. 6, pp. 1146-1152, July 1991.

[3] R. D. Zimmerman and H. D. Chiang, "Fast decoupled power flow for unbalanced radial distribution systems," IEEE Trans. Power Syst., vol. 10, pp. 2045-2052, Nov. 1995.

[4] W. M. Kersting and L. Willis, "Radial Distribution Test Systems, IEEE Trans. Power Syst.,", vol. 6, IEEE Distribution Planning Working Group Rep., Aug. 1991. Models, Chapman \& Hall/CRC, Boca Raton, 2007.

[5] A. R. Bergen, Power Systems Analysis, Prentice-Hall, Englewood Cliffs, NJ, 1986.

[6] Ray Daniel Zimmerman," Comprehensive Distribution Power Flow:Modeling, Formulation, Solution Algorithms and Analysis" Cornell University 1995.

[7] A. Augugliaro, L. Dusonchet," A backward sweep method for power flow solution in distribution networks" Electrical Power and Energy Systems 32 (2010) 271-280.

[8] Bompard, E. Carpaneto," Convergence of the backward/forward sweep method for the load-flowanalysis of radial distribution systems" Electrical Power and Energy Systems 22 (2000) 521-530.

[9] Michael McAsey and LibinMou," Convergence of the Forward-Backward Sweep Method inOptimal Control" IL 61625.

[10] Chiang, H.D.: 'A decoupled load flow method for distribution power network algorithms, analysis and convergence study", Electrical Power and Energy Systems, 13 (3), 130-138, 1991.

[11] M.E. Baran, F.F. Wu, Optimal Sizing of Capacitors Placed on a Radial DistributionSystem, IEEE Transactions on Power Delivery, Vol.4, no:1, pp.735-743, 1989.

[12] Goswami, S.K and BASU, S.K.: 'Direct solution of distribution systems',IEE Proc. C. , 188, (I),pp. 78-88, 1991.

[13] G.B. Jasmon, L.H.C. Lee, Distribution Network Reduction for Voltage StabilityAnalysis and Load Flow Calculations, Electrical Power \& Energy Systems, Vol.13,no:1,pp. 9-13, 1991.

[14] B. Stott, "Review of Load-Flow Calculation Methods", Proceedings of The IEEE, Vol. 62, No. 7, July 1974, pp. 916-929

[15] C.L Wadhwa, "Electrical Power Systems", New Age International, 2010 edition

[16] R. SrinivasaRao, K. Ravindra,"Power Loss Minimization in Distribution System Using Network Reconfiguration in thePresence of Distributed Generation" IEEE Transactions On Power Systems, Vol. 28, No. 1, February 2013.

[17] S.Ganesh, "Network reconfiguration of distribution system using artificial bee colony algorithm", WASET, International Journal of Electrical, Electronic Science and Engineering, Vol:8No:2, 2014

[18] Fukuyama, Y., Endo, H. and Nakanishi, Y. "A Hybrid System for Service Restoration Using Expert System and Genetic Algorithm". Intelligent Systems Applications to Power Systems, pp. 394-398, 1996.

[19] Gray Miller, Art Storey, Subramanian V. Vadari and Kathy Brewer, "Experiences Using the Dispatcher Training Simulator as a Training Tool", IEEE Transactions on Power Systems, Vol. 8, No. 3, pp. 1126-1132, 1993.

[20] Hain, Y. and Schweitzer, I. "Analysis of the Power Blackout of June 8, 1995 in the Israel Electric Corporation", IEEE Transaction on Power System, Vol. 12, No. 4, pp. 1752-1758, 1997.

[21] Huang, J.A., Galiana, F.D. and Vuong, G.T. "Power System Restoration Incorporating Interactive Graphics and 
Optimization", IEEE Power Industry Computer Application Conference, pp. 216-222, 1991.

[22] HyungSeon Oh, "A New Network Reduction Methodology for Power System Planning Studies", IEEE Transactions on power systems, Vol. 25, No. 2, pp. 677-684, 2010.

[23] Kafka, R.J., Penders, D.R., Bouchey, S.H. and Adibi, M.M. "Role of Interactive and Control Computers in the Development of a System Restoration Plan", IEEE Transactions on Power Apparatus and Systems, Vol. 101, No. 1, pp. 43-52, 1982.

[24] Kafka, R.J., Penders, D.R., Bouchey, S.H. and Adibi, M.M. "System Restoration Plan Development for a Metropolitan Electric System", IEEE Transactions on Power Apparatus and Systems, Vol. 100, No. 8, pp. 3703-3713, 1981.

[25] Komai, K., Matsumoto, K. and Sakaguchi, T. "Analysis and Evaluation of Expert's Knowledge for Power System Restoration by Mathematical Programming Method", IEEE International Symposium on Circuits and Systems, Vol. 2, pp. 1895-1898, 1988.

[26] LiBao Shi H.L. Ding and Zhao Xu, "Determination of Weight Coefficient for Power System Restoration", IEEE Transactions on Power Systems, Vol. 27, No. 2, pp. 1140-1141, 2012.

[27] Mariani, E., Mastroianni, F. and Romano, V. "Field Experiences in Reenergization of Electrical Network from Thermal and Hydro Units", IEEE Transactions on Power Apparatus and Systems, Vol. 103, No. 7, pp. 1707-1713, 1984.

[28] Mawale, M.V. and Gandole, Y.B. "Analysis of Optimal Route Algorithms Under Constraint Conditions", International Journal of Computer Science and Information Technologies, Vol. 2, No. 6, pp. 2614-2619, 2011.

[29] Mehdi Rafian, Daniel Kirschen and Steven Silverman, "Evaluating A Restoration Tool Using Consolidated Edison's Training Simulator", IEEE Transactions on Power Systems, Vol. 11, No. 3, pp. 1636-1642, 1996.

[30] Men-Shen Tsai, "Development of an Object-Oriented Service Restoration Expert System with Load Variations", IEEE Transactions on Power Systems, Vol. 23, No. 1, pp 219-225, 2008.

[31] Mohanty, I., Kalita, J., Das, S., Pahwa, A. and Buehler, E. "Ant Algorithms for the Optimal Restoration of Distribution Feeders During Cold Load Pickup", Swarm Intelligence Symposium, Proceedings of the IEEE, pp. 132-137, 2003.

[32] Nagata, T. and Sasaki, H. "A Multi-Agent Approach to Power System Restoration", IEEE Transactions on Power Systems, Vol. 17, Issue 2, pp. 457-462, 2002.

[33] Nagata, T., Sasaki, H. and Yokoyama, R. "Power System Restoration by Joint Usage of Expert System and Mathematical Programming Approach", IEEE Transactions on Power Systems, Vol. 10, No. 3, pp. 1473-1479, 1995.

[34] Nagata, T., Tao, Y., Tahara, Y., Aoyama, T., Fujita, H. and Koaizawa, M, "Development of Bulk Power System Restoration simulator by means of Multi agent approach", The 47th IEEE International Midwest Symposium on Circuits and Systems, pp. 337-340, 2004.

[35] Olof Samuelsson, Lars Lindgren and Bo Eliasson, "Simulated Power System Restoration", 43rd International Universities Power Engineering Conference, pp. 1-5, 2008.

[36] Rahman, S. "Artificial Intelligence in Electric Power Systems - A survey of the Japanese Industry", IEEE Transactions on Power System, Vol. 8, No. 3, pp. 1211-1218, 1993.

[37] Ramon Nadira, Tomas E. Dy, Liacco and Kenneth A. Loparo, "A Hierarchical Interactive Approach to Electric Power System Restoration", IEEE Transactions on Power Systems, Vol. 7, No. 3, pp. 1123-1131, 1992.
[38] Roger Kearsley, "Restoration in Sweden and Experience Gained from the Blackout of 1983", IEEE Transactions on Power System, Vol. 2, No. 2, pp. 422-428, 1987.

[39] Sahar Idwan and Wael Etaiwi, "Dijkstra Algorithm Heuristic Approach for Large Graph", Journal of Applied Sciences, Vol. 11, No. 12, pp. 2255-2259, 2011.

[40] Sakaguchi, T. and Matsumoto, K. "Development of a Knowledge Based System for Power System Restoration", IEEE Transactions on Power Apparatus and Systems, Vol. 102, No. 2, pp. 320-329, 1983.

[41] Seung-Jae Lee, Seong-Il Lim and Bokk-Shin Ahn, "Service Restoration of Primary Distribution Systems Based on Fuzzy Evaluation of Multi-Criteria", IEEE Transactions on Power Systems, Vol. 13, No. 3, pp. 1156-1163, 1998.

[42] Shahnawaz Ahmed, Narayan Chandra Sarker, Azhar B. Khairuddin, Mohd Ruddin B. Abd Ghani and Hussein Ahmed, "A Scheme for Controlled Islanding to Prevent Subsequent Blackout", IEEE Transactions on Power systems, Vol. 18, No. 1, pp. 136-143, 2003.

[43] Shimakura, K., Inagaki, J., Matsunoki, Y., Ito, M., Fukui, S. and Hori, S. "A Knowledge Based Method for Making Restoration Plan of Bulk Power System", IEEE Transactions on Power Systems, Vol. 7, No. 2, pp. 914-920, 1992.

[44] Stefano Barsali, Romano Giglioli, Davide Poli, Marino Sforna, Roberto Salvati and Roberto Zaottini, "The Restoration of An Electric Power System: International survey and discussion of possible innovative enhancements for the Italian system", Electric Power Systems Research, Vol. 78, pp. 239-247, 2008.

[45] Sudhakar, T.D. and Srinivas, K.N. "Power System Reconfiguration Based on Prim's Algorithm", 2011, 1st International Conference on Electrical Energy System, pp. 12-20, 2011.

[46] Sudhakar, T.D., Shanmuga Vadivoo, N., Mary Raja Sulochanal, S. and Ravichandran, S. "Supply Restoration in Distribution Networks Using

[47] Dijkstra's Algorithm", International Conference on Power System Technology, pp. 640-645, 2004 